\title{
The Development of a Typology of Abusive Coaching Behaviours Within Youth Sport
}

\author{
Elaine Raakman', Kim Dorsch ${ }^{2}$ and Daniel Rhind ${ }^{3}$ \\ 1Justplay Inc., Burlington, ON, Canada \\ E-mail: elaineraakman@wejustplay.com \\ ¿University of Regina, Saskatchewan, Canada \\ ${ }^{3}$ Centre for Youth Sport and Athlete Welfare, Brunel University, UK
}

\begin{abstract}
The purpose of this article was to create the Typology of Coaching Transgressions model (TOCT), which is concerned with abuse, neglect and violence in youth sport. Comments provided by the Justplay Behaviour Management Program from two competitive hockey associations and one large soccer association were analyzed and sorted to assess the utility of the model to capture inappropriate coaching behaviours. A total of 540 comments were examined deductively using the TOCT. Approximately $80 \%$ of coaching transgressions were of an indirect nature (i.e., not directed at the athlete specifically), indicating that young athletes are exposed to forms of abuse, neglect, and violence that may create harm in ways not yet fully understood. These findings illuminate the importance of understanding the nature and impact of coaching conduct on youth sport participants.
\end{abstract}

Key words: Abuse, Ethics, Youth-Sport Coaching

\section{INTRODUCTION}

There is evidence that suggests the coach is the most influential person in the youth sport environment ${ }^{1,2}$. In fact, results from a survey in Quebec, Canada, indicated that in the sporting context $96 \%$ of children surveyed felt that their coach was more influential than their parents or teachers ${ }^{3}$. As such, coaches play a fundamental role in facilitating the psychological $^{4}$, behavioural ${ }^{5}$, emotional ${ }^{6}$, as well as the social and moral $^{7}$ development of young people. Coaching has also been linked with a range of positive outcomes such as the development of life skills ${ }^{8}$ and self-esteem ${ }^{6}$.

Despite these well documented positive outcomes, the environment within youth sport may also expose youth to various forms of negative coach behaviours including emotional abuse $^{9}$ and sexual abuse ${ }^{10}$. Youth sport, therefore, holds great potential to positively affect youth $^{11,12,13}$, as well as, produce outcomes that are potentially negative ${ }^{14,15,16}$. As a result, it is incumbent upon those with a vested interest in youth sports to investigate and develop best practices that ensure positive outcomes and protect the rights of children. 
In order to investigate youth sport environments, as well as to develop educational programs, evaluate interventions, provide support mechanisms, and manage expectations of, for, and about coaches, it is essential that we cultivate a clearer understanding of the nature and scope of inappropriate coaching conduct. By categorizing and defining detrimental behaviours we could be better equipped, as researchers, administrators, and coach educators to decrease the vulnerability of youth participants to abuse and negative outcomes associated with competitive sports.

Based on an extensive review of literature, personal experience as a sport journalist, and current position as Secretary of the Committee on the Rights of the Child, David ${ }^{17}$ proposed a typology of the main forms of abuse, neglect, and violence in competitive youth sport that highlighted four key areas of abuse: physical (e.g., striking an athlete), psychological (e.g., belittling or humiliating an athlete), sexual (e.g., inappropriate touching or sexual advances), and neglect (e.g., a lack of care for the athlete's health). This model appears to be consistent with previous research and expert opinion ${ }^{17,18}$. We argue that this approach may only tell part of the story. These categories of abuse focus on behaviours by the coach which target the athlete. However, simply being exposed to abusive behaviours from the coach may have a negative impact regardless of whether they are targeted at an athlete or observed by an athlete when targeted at another coach, athlete, or spectator.

Recently, Omli and $\mathrm{LaVoi}^{19}$ provided support for this notion of an indirect form of abusive coaching when they introduced the concept of background anger within the youth-sport environment. Background anger (BA) is defined as the presence of a verbal, nonverbal, or physical conflict between two or more individuals (typically adults) that children observe as bystanders $^{20,21}$. Omli and LaVoi astutely consider the importance of examining the nature, frequency, and outcomes associated with background anger with the understanding that although conflicts in youth sport are often reported between adults (parents, coaches, officials), they occur in the presence of children $^{22,23}$.

Omli and LaVoi also speculate that it would be difficult to imagine, outside the home, another environment where children are exposed to the variety of adult background anger that occurs at youth-sport events. Importantly, results of Omli and LaVoi note that BA appears to increase in the sport context as age and skill increase. They found examples of BA in the youth-sport context including, verbal anger (yelling), non-verbal anger (avoidant communication, eye-rolling, stomping up and down sidelines), and physical anger (pushing, punching, grabbing), all of which are potentially very distressing to children. Perhaps most interesting was that these behaviours were performed by the parents toward the coaches and officials. To date, no research has been found identifying and quantifying the extent to which coaches perform these behaviours.

It is important to identify and acknowledge these behaviours as there is a significant amount of research outside the youth-sport environment to suggest that BA has profound effects on the behaviour of children. For example, Cummings [20] reported that in dysfunctional family settings, young children responded to BA with heightened symptoms of stress, negative emotional responses, and by becoming more aggressive with peers. Additionally, Cummings et al. [21] report that all angry exchanges, even those that are non-verbal, evoke negative emotions in children. While physical-verbal altercations are interpreted as the most consequential in regards to children's emotions, unresolved anger induces more distress in children than resolved anger. Supporting research suggests that observing angry, inter-adult exchanges induces immediate distress in children ${ }^{24}$ even to the point of a heightened physiological response ${ }^{25,26}$.

These observations are extremely pertinent when we consider outcomes for youth 
participating in organized sport environments. Although there is little research quantifying the frequency in which children involved in youth sport are exposed to angry exchanges (often unresolved, due to the nature of the sport environment), we know that experientially and anecdotally, it is relatively consistent. We also know, from previous research, that children playing youth sports model adult behaviour ${ }^{2,27,28}$ in those environments. In fact, a direct correlation between negative coach conduct and negative player conduct has recently been reported ${ }^{2,5}$. In short we are inadvertently supporting situations and systems that may be causing emotional, psychological, and even physiological harm to children participating in competitive youth sports. Not only are children being exposed to angry adult exchanges, but we now know from research that they are likely to model that behaviour.

In the model presented by David [17], direct forms of physical, psychological, sexual, or neglectful abuse are identified. Based on the concept of background anger, we argue that these abuses may also occur in an indirect form. In other words, through observing two adults in the sport environment fighting (physical), being verbally abusive to one another (psychological), inappropriately touching another athlete (sexual), or through making another player play on through injury (neglect), an athlete may be exposed to indirect forms of abuse. To reflect this, we developed an expanded version of David's [17] model through creating a mirror image of the direct abuses to suggest that these could all happen indirectly (see Figure 1). As they relate specifically to coaches' conduct, we refer to this new model as the Typology of Coaching Transgressions (TOCT).

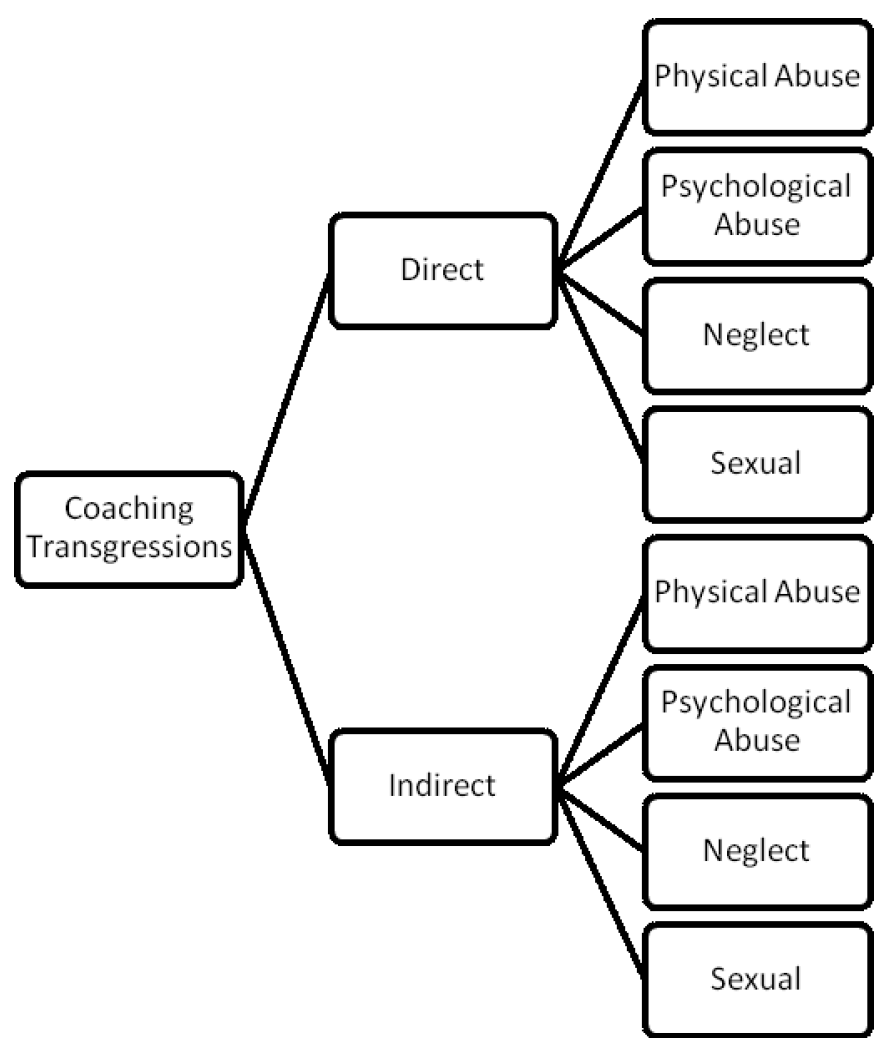

Figure 1. Typology of Coaching Transgressions 
The first purpose of the present study was to examine whether or not this model captures the full range of inappropriate coaching behaviours by conducting a critical incident analysis (CIA), which is a technique originally developed to facilitate the investigation of errors within the aviation industry ${ }^{29}$. This approach acknowledges that not all incidents lead to accidents; rather, it emphasises that it is through understanding such incidents that preventative steps can be taken to avoid accidents. Subsequently, researchers have advocated the application of CIA to other domains including safety in anaesthesia ${ }^{30}$ and the investigation of cases of child abuse within social work ${ }^{31}$. Thus, incidents of negative coaching behaviours will be analyzed to identify potential cases of abusive coaching and hence test the validity of the proposed model.

Obtaining valid and unbiased reports of these kinds of negative behaviours, or even coaching behaviours in general, has proven to be somewhat of a challenge. Indeed, researchers $1,4,17,18,32$ and governing agencies ${ }^{33-35}$ from around the world acknowledge that there is a desperate need for a universal, independent monitoring tool for youth sport. In his critical review on human rights in youth sport, David [17] suggests that the absence of independent data severely limits important avenues of reform such as awareness raising initiatives and policy-making. This concern is reinforced by a statement published by the Australian Sport Commission in 1999: "Without data, it is impossible to make progress (or at least to know if progress is being made and, if so, whether it bears any resemblance to the intended outcomes)" [cited in 17, p. 12].

Recognizing the global paucity of quantitative data available to youth-sport administrators and researchers across all levels of competition, Justplay Sports Services, Inc. designed a tool known as the Justplay Behaviour Management Program (JBMP). This instrument measures and monitors the conduct of youth-sport participant groups. JBMP has been collecting data regarding the conduct of participant groups (players, coaches, spectators) in the youth team sport environment since $2001^{36}$. The JBMP empowers youthsport administrators to make data-driven staffing and policy decisions regarding any action or inaction that may be necessary to anticipate, respond to, or avoid problematic behaviour from coaches, players, or spectators ${ }^{36}$. In addition to providing sport organizations across Canada and the U.S. with information that helps them understand and identify the factors influencing conduct, it also identifies trends in behaviour (positive and negative) that provide important insights into a particular sporting environment ${ }^{36}$. Consequently, the second aim of the present research was to examine the utility of the JBMP as a tool for capturing negative coaching behaviours that can be assessed and analyzed within the typology model.

\section{METHOD}

\section{STUDY OVERVIEW}

The Justplay Behaviour Management Program (JBMP) involves game officials as observers to provide data about the game environment, and is therefore considered a naturalistic study of competitive youth sports. In the present study, researchers analyzed the officials' card comments related to games in which the behaviour of players, coaches or spectators was viewed as unacceptable (i.e., a critical incident). Comments were deductively analyzed through categorizing them into the various elements of the Typology of Coaching Transgressions.

The game official is considered to be the most appropriate source due to their unique contribution to the game for a number of reasons: a) their role is to ensure the game is played as fairly as possible; b) they are the only participant group with no stake in the outcome of the game; c) they are the only participant group that is periodically and systematically held accountable to their level of expertise; d) they are paid for their neutrality and independent 
services; and e) they are responsible for the safety of the participants. As such the JBMP involves the official to independently monitor the conduct of players, coaches, and spectators on a game-by-game basis (for more information regarding the JBMP, see [36]).

\section{DATA COLLECTION PROCEDURES AND INSTRUMENT}

Every official that participates within the context of the game, regardless of his or her role (e.g., head referee, linesman, etc.), independently completes a Justplay Conduct Report Card (subsequently referred to as cards). The number of cards per game is related to the number of officials on the playing field. Depending on the sport, there can be as few as one card per game (i.e., one official per game) or as many as six. Compliance rates for the association's officials (i.e., the percentage of officials reporting on behaviours per season) can then be computed based upon the percentage of cards submitted by officials relative to the total number of cards available. Compliance rates for the associations involved in this study are reported in the following section describing the sample.

On the card, officials rate the overall behaviour (conduct) of the home and visiting players, coaches, and spectators on a scale of 1 (Very Good) to 5 (Very Poor). Ratings of 4 and 5 for any of the six participant groups (i.e., home and away players, coaches, and spectators) are considered to be critical incidents (i.e., those that are identified as games in which the conduct of the participant group was deemed unacceptable by the official). Along with these behavioural ratings, the officials are provided with a space to write comments regarding their observations of the participant groups' behaviour. For the purposes of this study, only cards that contained a critical incident (poor or very poor rating) for coaching behaviours and associated official comment were selected for analysis.

Multiple blank cards are provided to each official in a pad format at the start of the season and officials can keep track of their ratings for games they officiated on the pad. Officials then $\log$ on to the Justplay website and enter their card data on-line. All data entered by officials are cross-tabulated against their age, years of experience, level of certification, and role within the game. In addition to providing a means of data inputs and outputs, the JBMP also provides administrators of each sport organization access (on a password-privileged basis) to their information entered into the database, displayed as a library of dynamic graphs. The real-time nature of the graphs provides volunteer (and professional) administrators with an unprecedented ease of identifying short and long term trends in behaviour unique to their organization. This is the tool aspect of the JBMP. Additionally, the JBMP provides a monthly summary report, which highlights both positive and negative trends within the organization and then compares these trends to other general trends within that sport. Suggestions are made to respond to any identified issues and concerns, and if necessary policy analyses are conducted. These services are considered to be the program aspect of the JBMP. Importantly, once monitoring is in place, the success of any strategy implemented to ameliorate an identified problem can be measured. The JBMP has collected data for various ice hockey, soccer, football, baseball, basketball, and gymnastics organisations.

\section{SAMPLE}

Although there were a number of different team sports from which to choose within JBMP, the data chosen for analysis for this study came from the 2007 season of two ice hockey and one soccer associations. The authors felt it was important to select one contact sport (ice hockey) and one non-contact sport (soccer) for analysis to help determine whether or not coaching conduct is reflective of sport or whether it transcends sport and is relatively 
consistent. Other considerations regarding the organisations that were selected for analysis included: representativeness in regards to age (divisions), skill (leagues), size of the organisation, and amount of data available. Both ice hockey associations were from large, urban, Canadian centres $(+500,000)$, while the soccer association that provided the data was from a large, urban, Canadian centre $(+1,000,000$ total population). Each of the organizations chosen provide sport services to children and youth ranging from Novice (6 and 7 years old) to Juvenile (17 and 18 years old), and include both house-league (community based) and rep (travel teams) skill levels. The JBMP does not, for privacy reasons, collect any personal data regarding the coaches.

Ice hockey was chosen as it is a youth sport that attracts a considerable amount of negative media publicity in North America with regard to participant group conduct ${ }^{37}$ and therefore offered researchers a unique insight into the behaviours associated with this sport. Hockey Association A employed a total of 199 officials and had a compliance rate of 65.4\%. Hockey Association B employed 252 officials and had a compliance rate of 56.4\%. Each game played during the season had up to three officials on the ice which provided a total of 20,766 cards. The number of cards containing critical incidents involving coaches that were available for analysis was 2916 (14\%). Of these, 401 (13.8\%) cards contained comments from officials and were included in the final data set.

Soccer was chosen as it represents one of the largest organised sports for children and youth (in terms of numbers of participants in the world). Furthermore, soccer governing bodies are seeking solutions to the violence and abuse occurring on the field and sidelines at ever increasing rates ${ }^{38}$. The soccer association had both an indoor and outdoor season. The indoor season employed 283 officials and had a compliance rate of $15.2 \%$. The outdoor season involved 265 officials and had a compliance rate of $14.4 \%$. The potential number of cards available for analysis from these associations together was 2,293. After delimiting the cards to those which contained only critical incidents involving coaches, the total number of cards available for analysis was 174 (7.6\%). Officials' comments regarding coaches were provided on 139 of these cards (79\%) and subsequently were added to the hockey cards to comprise the final data set. These 540 cards with comments were analyzed. It is important to note that the compliance for soccer officials is lower than that of hockey officials. Anecdotally, Justplay experts suggest that this trend is due to the number of young officials in the soccer domain. The majority of officials in soccer are 16 years old or younger, and without mandatory participation that is enforced by the organization (as was the case with the hockey organizations), compliance rates are generally poorer and thus critical incidents in soccer may in fact be under reported.

\section{DATA ANALYSIS}

Each of the three researchers was assigned to analyse the comments from one association. The researchers then thoroughly read through the card comments until they were familiar with the data. In bi-weekly meetings, the independent examinations made by each of the researchers were reviewed until a consensus on theme development was reached. Each card comment was categorized into one of the themes within the TOCT through deductive content analysis (i.e., direct or indirect physical, psychological, sexual, or neglect). The comments within each theme were then inductively content analysed by each researcher to highlight lower-order themes. These themes were then combined across the three associations to generate a final set of lower-order themes. Any comments which were deemed relevant, but which did not fit into the proposed model, were then inductively analysed to identify any other potential themes. 


\section{RESULTS}

Examples and explanations are provided for each of the higher-order themes proposed by the TOCT. It is important to note that under both the direct and indirect sides of the model the second higher-order theme, sexual, which would include all comments describing any behaviours of explicit or implicit sexual harassment, contained no examples and will not therefore be addressed at this time. A brief summary of themes are presented in Table 1, while Figure 2 displays the percentage of comments categorized under each theme.

Table 1. Typology of Coaching Transgressions: Identified Higher and Lower Order Themes

\begin{tabular}{|c|c|}
\hline Type of Coaching Transgression & Examples \\
\hline \multirow[t]{3}{*}{ Direct physical abuse } & - justification of player's behaviour \\
\hline & - reinforcing injurious behaviour \\
\hline & - encouraging fighting or physical behaviour \\
\hline \multirow[t]{6}{*}{ Direct psychological abuse } & - yelling/swearing at players \\
\hline & - demoralization \\
\hline & - running up the score \\
\hline & - justifying racial slurs \\
\hline & - taunting fans \\
\hline & - threatening own player \\
\hline \multirow[t]{2}{*}{ Direct neglect } & - lack of discipline/control \\
\hline & - lack of care \\
\hline Direct modeling behaviours & - deliberate breaking of rules using players \\
\hline \multirow[t]{3}{*}{ Indirect physical abuse } & - involvement in physical behaviours \\
\hline & - throwing objects at officials \\
\hline & - threatening behaviour \\
\hline \multirow[t]{8}{*}{ Indirect psychological abuse } & - harassment of officials \\
\hline & - yelling at others \\
\hline & - challenging calls \\
\hline & - abusive behaviour \\
\hline & - foul language/emotional displays \\
\hline & - removal from game \\
\hline & - insinuating opponent not injured \\
\hline & - intimidation \\
\hline \multirow[t]{4}{*}{ Indirect modeling behaviours } & - penalization of coach \\
\hline & - disrespect of officials, game, and opponents \\
\hline & $\begin{array}{l}\text { - general negative behaviour/poor } \\
\text { sportsmanship }\end{array}$ \\
\hline & - lack of rule knowledge \\
\hline
\end{tabular}

\section{DIRECT PHYSICAL ABUSE}

This category included all behaviours (2.4\% of the comments) where the coach explicitly promoted or justified using physically aggressive behaviours by or toward the players of his or her team, or the opposing team. For example, a comment classified under 'reinforcing injurious behaviour' described, "At the end of the game, while in my dressing room, I could hear the coach glorifying the penalties his team had taken. He even congratulated them for taking so many." 


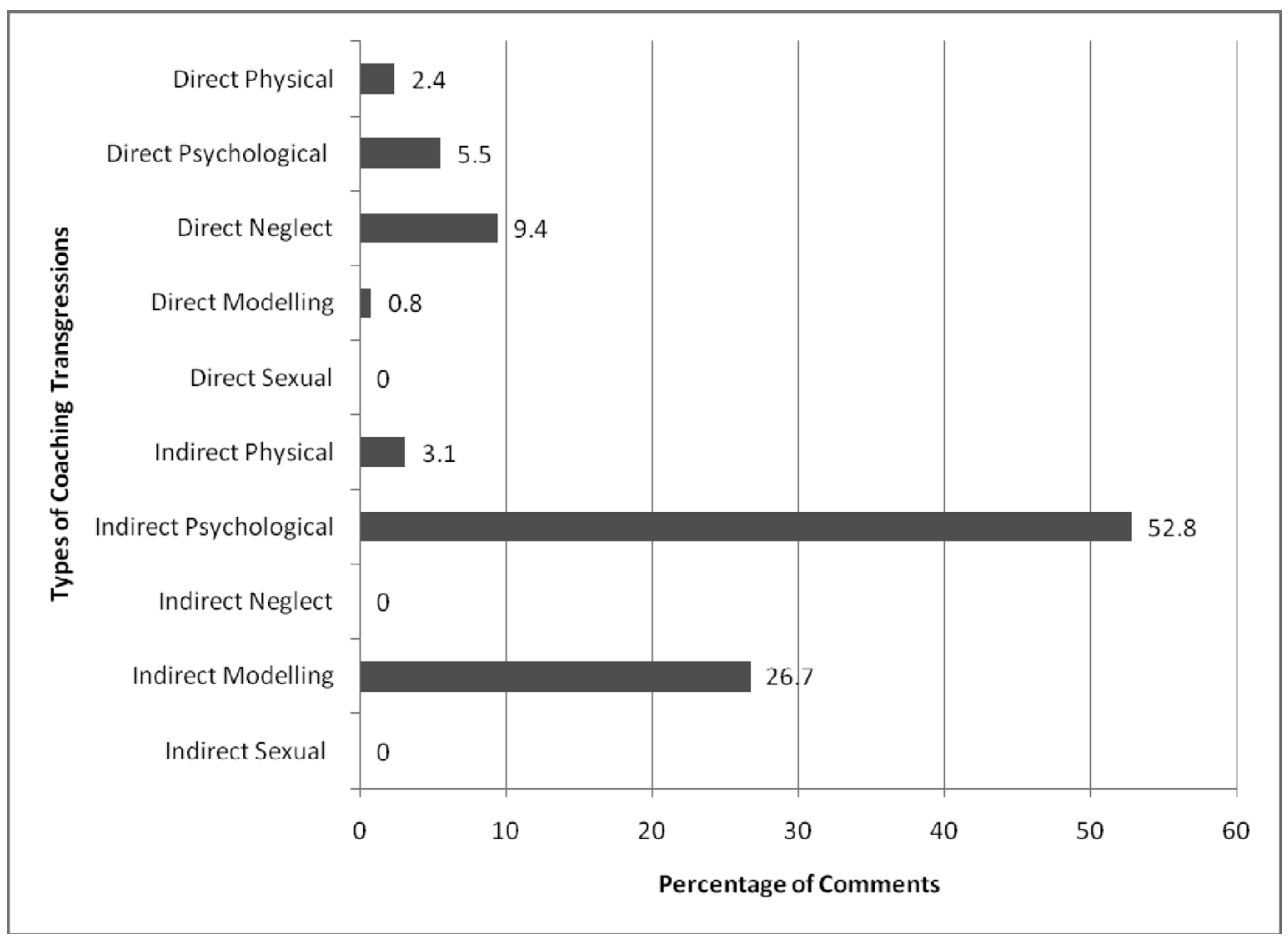

Figure 2. Percentage of Comments in Each Category of Coaching Transgressions

\section{DIRECT PSYCHOLOGICAL ABUSE}

This category included all comments describing observable psychological tactics $(5.5 \%$ of comments). An example from the 'threatening own player' category included this observation, “.......(team) coach was verbally abusive towards his goaltender to the point that if I were the father of the goalie I would have filed a complaint with..........(the hockey association). This coach needs to take some anger management courses."

\section{DIRECT NEGLECT}

This category typified neglectful or lazy coaching (9.4\% of comments). Coaches have an obligation to provide direction and a framework for behaviour and when they fail to do this they are being neglectful. For example this comment was classified under 'lack of control', “.....Coaching staff has no self-control with themselves and no control over their players."

\section{INDIRECT PHYSICAL ABUSE}

This category reflected behaviour that was seen to have a definite physical attribute but the physicality was not directed at the players ( $3.1 \%$ of comments). A sample comment from the involement in physical behaviour category included, "Coach in altercation at end of match with coach."

\section{INDIRECT PSYCHOLOGICAL ABUSE}

This category represented a variety of behaviours, interpreted by the researchers $(52.8 \%$ of 
comments), to have a negative emotional connotation (i.e., anger or attempts to berate or intimidate another individual). A disturbing comment from the lower order theme 'abusive behaviour' included the following comment, "Head coach from the .....(team) disputed my call during the game. I let it go and he started up after the game and said to me, 'f_king bad call'. In that case I issued him a game misconduct [penalty with up to one game suspension]. On the way out of the rink he stopped me and asked me if I was $f$ _king stupid. In this event he also picked up a gross misconduct [penalty with up to an additional four game suspension] for his remarks."

\section{INDIRECT NEGLECT}

Once the comments were categorized according to the TOCT, the researchers discovered that many comments did not fit the model. To capture the collective nature of these uncategorized comments, the researchers inductively reasoned that a new higher-order theme was needed. The TOCT model was expanded to include this new category, entitled Modeling Behaviours. The remaining comments were then classified as Direct Modeling Behaviours or Indirect Modeling Behaviours, with inductively reasoned appropriate lowerorder themes. Examples of the new categories are provided below. The revised model is depicted in Figure 3.

\section{DIRECT MODELING BEHAVIOR}

This category typified behaviours that showed the coach explicitly encouraging players to play outside of the rules $(0.8 \%$ of comments). An example from this theme included, "Assistant coach threatened to have his players cause problems on the ice due to the poor officiating. He stated, "I am going to make your game uncontrollable since your officiating sucks."

\section{INDIRECT MODELING BEHAVIOURS}

An example from the poor sportsmanship category included, " coach, players and parents demonstrated the worst sportsmanship that I have ever seen in 11 years of officiating - especially at the under 12 level. This coach should not be coaching young children - they are taught to how to foul as they don't have the skill to play at this level. Absolutely no skill development from the start of the season (I saw them then)." This final category contained all behaviours that are being unconsciously or indirectly modeled for the athletes $(26.7 \%$ of comments).

In summary, of the 540 comments, 509 were associated with negative coach conduct (94.3\%). There were 417 (82\%) comments classified as indirect transgressions, and 92 (18\%) comments classified as direct transgressions. Indirect Psychological was the category containing the most comments at 269 (52\%) overall, followed by Indirect Modelling Behaviour with 136 comments (26\%), and finally Direct Neglect with 48 comments (9\%). Within the indirect categories, most comments revolved around the Harassment of Officials (77 comments; Indirect Psychological), while from the direct categories the most comments were regarding Lack of Discipline/Control (Direct Neglect) with 47.

\section{CONCLUSION}

The present study had two key aims. The first was to investigate the capability of a newly developed model of coaching transgressions to capture critical incidents. The second was to assess the utility of the Justplay program as a method via which coaching behaviours can be captured. Overall, both of these aims were achieved by the research and it is now argued that 


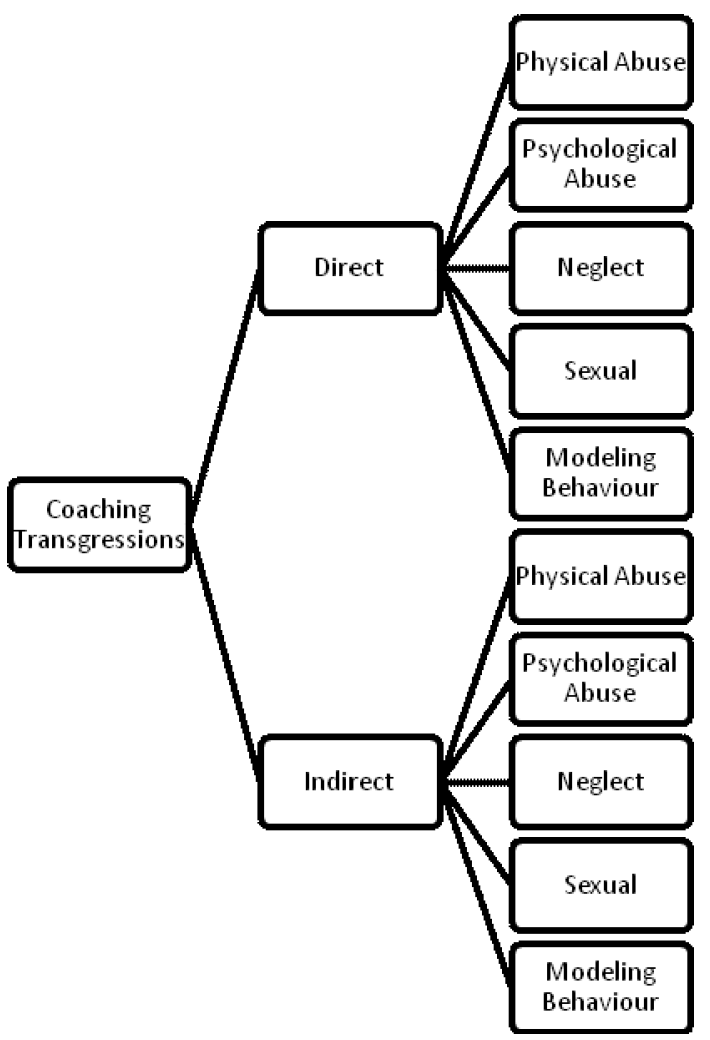

Figure 3: Final Typology of Coaching Transgressions

both the TOCT and JBMP represent key resources to support the drive towards optimizing the youth-sport environment.

The present research builds upon the typology of the main forms of abuse, neglect, and violence in competitive youth sports ${ }^{17}$ by advocating the inclusion of indirect abuses. This builds on the work of Omli and $\mathrm{LaVoi}^{19}$ to further emphasize that an environment can be abusive for a young person without them being the victim of direct abuse. The extremely high prevalence of indirect abuses relative to direct abuses suggests that the conceptualization of negative coaching in youth sport prior to this paper's examination may have been too narrow. As a result of this, we may not have been obtaining a complete and accurate impression of the wide range of negative coaching behaviours which may have been occurring within youth-sport environments across the world.

Many examples of both direct and indirect coaching transgressions were highlighted within the card comments, supporting the argument that this is a significant issue within youth sport. A key finding was that $82 \%$ of the categorized comments related to indirect abuses. This evidence of background anger as manifested by the coach gave strong support for the assertion of the TOCT model that it is important to expand David's [17] model to include those abuses not directly involving the athlete alongside those which the coach directs toward the athletes themselves. The exposure of young athletes to indirect psychological abuses appears to be a particularly significant issue which merits further investigation. 
Equally important was the discovery of the modelling behaviour category, which captured behaviours previous research 2, 5, 27, 28 has cautioned against. Young children and youth imitate adult behaviour (positive and negative). Whether or not the questionable actions of adults are conscious or unconscious, as the examples provided in these categories indicate, the outcomes for players subvert all the potential good the participation in youth sport should provide.

JBMP continues to collect data regarding the conduct of participant groups (players, coaches, spectators) in the youth, team-sport environment. The present research highlights the potential benefits of using this data to explore important research questions. JBMP not only provides a very useful resource for researchers, it can also be used to inform youth-sport administrators in making data-driven staffing and policy decisions regarding any action or inaction that may be necessary to anticipate, respond, or avoid problematic behaviour from coaches, players, spectators, or officials ${ }^{36}$.

The need to obtain valid and unbiased reports of negative coaching behaviours has been widely acknowledged by both leading researchers $1,4,17,18,32$, as well as governing agencies $^{33-35}$. The present study clearly demonstrates how JBMP can contribute to meeting this need.

There are some important limitations associated with the present study. The current study used data collected from the comment cards of youth-sport officials. The quality of this data can be influenced by the honesty and accuracy of the officials. Future research can help overcome this limitation through providing more guidance to officials on the type of information which is most helpful to record. Other data-collection methods can also be employed such as observations, interviews, questionnaires, and diaries involving all of the key stakeholders within youth sport (e.g., officials, coaches, parents, young athletes). A further limitation is that the data are constrained to the types of abuses that were witnessed by the officials in the competitive setting. This may well explain why no cases of direct or indirect sexual abuse were recorded. Inevitably, many coaching abuses will occur out of the sight of any officials or during practice and hence the current data will only ever represent a portion of the total number of direct and indirect coaching abuses. Finally, the present study was conducted on a Canadian sample. There remains great scope to assess the validity of the TOCT model within other cultures as well as to use JBMP to identify the prevalence, antecedents, and consequences of negative coaching within different populations, sports, and cultures.

The TOCT now opens many avenues for further research. Research has already been conducted into elements of the TOCT model such as direct emotional abuse ${ }^{9}$ and direct sexual abuse ${ }^{10}$. However, all of the other elements of TOCT now require exploration to identify the prevalence, antecedents, and consequences of all of these different types of abuse. Such work will inform the subsequent development of educational programs, implementation and evaluation of interventions, and the provision of support mechanisms to manage expectations of, for, and about coaches' conduct. The TOCT and JBMP represent important resources which can facilitate programs that are designed to reduce the prevalence of negative coaching within youth-sport environments. Through this, we can work towards creating effective coaching within youth-sport environments which subsequently can positively foster the development of young people.

\section{ACKNOWLEDGEMENTS}

The authors would like to thank those sport organizations involved with this project that have been trying to make the youth-sport experience a positive one. 


\section{REFERENCES}

1. Chow, G.M., Murray, K.E. and Feltz, D.L., Individual, Team, and Coach Predictors of Players' Likelihood to Aggress in Youth Soccer, Journal of Sport and Exercise Psychology, 2009, 31, 425-443.

2. Guivernau, M. and Duda, J.L., Moral Atmosphere and Athletic Aggressive Tendencies in Youth Soccer Players, Journal of Moral Education, 2002, 31(1), 67-85.

3. Coaching Association of Canada, Straight Talk About Children and Sport: Advice for Parents Coaches and Teachers, Coaching Association of Canada, 1996, 1-136.

4. Ciairano, S., Gemelli, F., Molinengo, G., Musella, G., Rabaglietti, E. and Roggero, A., Sport, Stress, Selfefficacy and Aggression Towards Peers: Unravelling the Role of the Coach, Cognition, Brain, and Behavior, 2007, 11(1), 175-194.

5. Arthur-Banning, S., Wells, M.S., Baker, B.L. and Hegreness, R., Parents Behaving Badly? The Relationship Between the Sportsmanship Behaviors of Adults and Athletes in Youth Basketball Games, 2009, Journal of Sport Behavior, 32(1), 3-18.

6. Smith, R.E., Smoll, F.L. and Cumming, S.P., Effects of a Motivational Climate Intervention for Coaches on Young Athletes' Sport Performance Anxiety, Journal of Sport and Exercise Psychology, 2007, 29(1), 39-59.

7. Shields, D.L., LaVoi, N.M., Bredemeier, B.L. and Power, C.F., Predictors of Poor Sportspersonship in Youth Sports: Personal Attitudes and Social Influences, Journal of Sport and Exercise Psychology, 2007, 29(6), 747-763.

8. Gould, D., Collins, K., Lauer, L. and Chung, Y., Coaching Life Skills Through Football: A Study of Award Winning High School Coaches, Journal of Applied Sport Psychology, 2007, 19(1), 16-37.

9. Gervis, M. and Dunn, N., The Emotional Abuse of Elite Child Athletes by Their Coaches, Child Abuse Review, 2004, 13(3), 215-223.

10. Brackenridge, C.H., Spoilsports: Understanding and Preventing Sexual Exploitation in Sport, Routledge, London, 2001.

11. Gibbons, S.L., Ebbeck, V. and Weiss, M.R., Fair-play for Kids: Effects on the Moral Functioning of Children in Physical Education, Research Quarterly for Exercise and Sport, 1995, 66, 247-255.

12. Malina, R.M. and Cumming, S.P., Current Status and Issues in Youth Sports, in: Malina, R.M. and Clark, M.A., eds., Youths Sports: Perspectives for a New Century, Coaches Choice, Monteray, CA, 2003, 7-25.

13. Seefeldt, V.D., Ewing, M.E. and Walk, S., Overview of Youth Sports Programs in the United States, Carnegie Council on Adolescent Development, Washington, DC, 1992.

14. Kavussanu, M., Motivational Predictors of Prosocial and Antisocial Behaviour in Football, Journal of Sports Sciences, 2006, 24(6), 575-589.

15. Shields, D.L., Bredemeier, B.L., LaVoi, N.M. and Power, C.F., The Behavior of Youth, Parents, and Coaches: The Good, The Bad, and The Ugly, Journal of Research in Character Education, 2005, 3(1), 43-59.

16. Weinstein, M.D., Smith, M.D. and Wiesenthal, D.L., Masculinity and Hockey Violence, Sex Roles, 1995, 33, 831-847.

17. David, P., Human Rights in Youth Sports: A Critical Review of Children's Rights in Competitive Sports, Routledge, New York, 2005.

18. Brackenridge, C., Pawlaczek, Z., Bringer, J.D., Cockburn, C., Nutt, G., Pitchford, A. and Russell, K., Measuring the Impact of Child Protection Through Activation States, Sport, Education and Society, 2005, 10(2), 239-256.

19. Omli, J. and LaVoi, N.M., Background Anger in Youth Sport: A Perfect Storm?, Journal of Sport Behavior, 2009, 32(2), 242-260.

20. Cummings, E.M., Coping with Background Anger in Early Childhood, Child Development, 1987, 58, 976984.

21. Cummings, J.S., Pellegrini, D.S., Notarius, C.I. and Cummings, E.M., Children's Responses to Angry Adult Behavior as a Function of Marital Distress and History of Interparent Hostility, Child Development, 1989 , 60, 1035-1043. 
22. Abrams, D. E., Message Posted on Electronic Mailing List, Youth Sport Newspaper Articles, archived at AbramsD@missouri.edu, 2006.

23. Kuyper, T., Daddy, Keep Your Pants On, Will You Please?, The Times Union, 2006, April 5, p. C2.

24. Harger, J. and El-Sheikh, M., Are Children More Angered and Distressed by Man-Child than Woman-Child Arguments and by Interadult versus Adult-Child Disputes?, Social Development, 2003, 12(2), 162-181.

25. Ballard, M.E., Cummings, E.M. and Larkin, K., Emotional and Cardiovascular Responses to Adults' Angry Behavior and To Challenging Tasks in Children of Hypertensive and Normotensive Parents, Child Development, 1993 64, 500-515.

26. El-Sheikh, M., Cummings, E.M. and Goetsch, V., Coping with Adults' Angry Behavior: Behavioral, Physiological, and Verbal Responses in Preschoolers, Developmental Psychology, 1989, 25, 490-498.

27. May, R.A.B., The Sticky Situation of Sportsmanship, Journal of Sport and Social Issues, 2001, 25, 372-389.

28. Vallerand, R.J., Deshaies, P. and Cuerrier, J., On the Effects of the Social Context on Behavioral Intentions of Sportsmanship, International Journal of Sport Psychology, 1997, 28, 126-140.

29. Flanagan, J. C., The Critical Incident Technique, Psychology Bulletin, 1954 51, 327-58.

30. Craig, J. and Wilson, M. E., A Study of Anaesthetic Misadventures. Anaesthesia, 1981, 36, 933.

31. Mills, C. and Vine, P., Critical Incident Reporting - An Approach to Reviewing the Investigation and Management of Child Abuse, British Journal of Social Work, 1990, 20, 215-220.

32. Coakley, J., Social Dimension of Intensive Training and Participation in Youth Sports, in: Cahil, B.R. and Pearl, A.J. eds, Intensive Participation in Children's Sports, American Orthopedic Society for Sports Medicine, Champaign, IL, Human Kinetics Publishers, 1993, p. 85.

33. Australian Sports Commission, Australian Confederation of Australian Sport, School Sport Australia, Standing Committee on Sport and Recreation, Committee of Education Systems Chief Executive Officers, National Junior Sport Policy (1994), A Review: Final report, National Junior Sport Policy Working Group, 1999.

34. The Committee on the Rights of the Child, Report of the Second Session, CRC/C/10, Geneva: UN, 1992.

35. United Nations Development Programme, Human Development Report 2002, Deepening Democracy in a Fragmented World, Oxford University Press, Oxford, 2000.

36. Raakman, E., Justplay: A Revolutionary Approach to Youth Sport Administration and Sportsmanship, Journal of Physical Education, Recreation and Dance, 2006, 77(6), 20-24.

37. Cribb, R., and Kelchman, L., Racial Complaints Take Leap, The Toronto Star, December 5, 2009, A1.

38. Brackenridge, C.H., Pitchford, A., Nutt, G. and Russell, K., Child Welfare in Football, Routledge, London, 2007. 